\title{
Powder and Solvent for Suspension for Injection in Pre-filled Syringe
}

National Cancer Institute

\section{Source}

National Cancer Institute. Powder and Solvent for Suspension for Injection in Pre-filled

Syringe. NCl Thesaurus. Code C149803.

Medicinal product consisting of a powder and solvent for suspension for injection

presented in a pre-filled syringe. The powder and solvent are contained in different

compartments of the pre-filled syringe, which contains all of the components necessary

to prepare the suspension for injection. 